\title{
A vermicompostagem como temática para a promoção da alfabetização científica
}

\section{RESUMO}

Aline Ferreira Torezin alinetorezin@gmail.com 0000-0001-6230-5211 Universidade Tecnológica Federal do Paraná, Curitiba, Paraná, Brasil.

Tamara Simone van Kaick tamara.van.kaick@gmail.com 0000-0003-2959-5223

Universidade Tecnológica Federal do Paraná, Curitiba, Paraná, Brasil.

\begin{abstract}
Este artigo faz uma análise qualitativa de uma Sequência Didática (SD) para o Ensino Fundamental, elaborada com o tema vermicompostagem para promover a Alfabetização Científica (AC). A SD é uma metodologia de ensino organizada e aplicada de forma a facilitar a aprendizagem. A AC é um processo contínuo de compreensão e aplicação de significados e conceitos científicos. A vermicompostagem é a reciclagem da matéria orgânica resultante da ação de minhocas e microrganismos, que foi aplicada na SD para a promoção do processo de investigação e da AC. Os alunos registraram os conteúdos assimilados durante a SD em diários de bordo, que foram analisados à luz dos 10 indicadores de AC propostos por Sasseron (2008). Os resultados da frequência dos indicadores foi: alta - para levantamento de dados; média - para estruturação do pensamento; baixa - para estabelecendo relações, sendo este último o elemento que deveria ser melhor trabalhado pelo ensino.
\end{abstract}

PALAVRAS-CHAVE: Sequência Didática. Indicadores. Estratégia Pedagógica. 


\section{INTRODUÇÃO}

O ensino de Ciências, embora muito instigante, na maioria das vezes limita-se a transmissão de conteúdos, onde os alunos são meros expectadores, sem contextualização, problematização e análise crítica dos conteúdos. Para Moraes (2002), a escola ainda está muito centrada na transmissão de conteúdos pelo professor, não oportunizando ao aluno/estudante um papel na produção deste conhecimento. Neste sentido, as aulas de Ciências precisam ser repensadas, buscando "promover a formação integral do cidadão, como ser pensante e atuante, e como responsável pelos destinos da sociedade." (LORENZETTI, 2000, p. 18).

No sentido de promover um processo de ensino e aprendizagem que pudesse inserir a Alfabetização Científica, e ao mesmo tempo promover a Educação Ambiental Crítica, com o objetivo de permitir o desenvolvimento do raciocínio lógico e explicação de fenômenos, as autoras desenvolveram uma Sequência Didática (SD) com o tema vermicompostagem para o ensino de Ciências. Foi utilizada a seguinte questão norteadora para o desenvolvimento da SD: qual a viabilidade da prática experimental de um vermicompostor a ser implementando no ambiente escolar, para favorecer a abordagem sobre a gestão de resíduos e o ciclo do alimento, a fim de promover a alfabetização científica no processo de aprendizagem dos educandos? Esta SD foi baseada nos princípios de Zabala (1998), utilizando diferentes formas de intervenção que possibilitem a interpretação, compreensão ou exposição de um fenômeno ou situação para as atividades desenvolvidas. Estas atividades foram agrupadas de acordo com os três momentos pedagógicos propostos por Delizoicov, Angotti e Pernambuco (2009). A abordagem didática baseado nos 3 momentos pedagógicos, permite uma visão mais abrangente e universal da realidade, onde o diálogo e a postura crítica do educador são fundamentais, além de favorecer a problematização constante e a construção coletiva do conhecimento. A SD foi então desenhada buscando incluir o desenvolvimento da Alfabetização Científica entre os alunos do 70 ano do Ensino Fundamental. Segundo Lorenzetti e Delizoicov (2001), a formação de sujeitos alfabetizados cientificamente é essencial dentro de uma postura crítica de educação, pois possibilita a compreensão e aplicação acerca dos assuntos científicos, na busca por um melhor entendimento do mundo.

A vermicompostagem, que é a técnica de compostagem que utiliza as minhocas que digerem os resíduos orgânicos, produzindo ao final do processo o húmus que é nutriente para o solo, ao ser desenvolvida no ambiente escolar, pode oportunizar a compreensão do ciclo do nutriente e do alimento, favorecendo desta forma a introdução da Alfabetização Científica com a aplicação de vários conceitos científicos. Esta temática permite ainda discussões relacionadas a geração, gerenciamento e tratamento dos resíduos orgânicos, produzidos durante o preparo das refeições da escola, o que fornece elementos essenciais aos alunos para repensarem as questões socioambientais relacionadas ao tema dos resíduos, que permeiam a realidade da comunidade onde vivem, elementos estes que são os pressupostos para a Educação Ambiental Crítica.

As atividades da vermicompostagem foram desenvolvidas durante as aulas de Ciências, envolvendo o trabalho prático de montagem e manutenção dos vermidigestores, que são as caixas onde acontece o processo da vermicompostagem, instigando o processo de investigação referente ao 
gerenciamento e tratamento dos resíduos orgânicos não cozidos no ambiente escolar. Os alunos sistematizaram os conceitos apreendidos em diários de bordo, organizados de forma coletiva (em trios) de todo o processo. Este artigo apresenta os resultados referentes aos diários de bordo dos alunos do 70 ano, que foram realizados durante a aplicação da SD referente ao tema da vermicompostagem. Os diários de bordo foram analisados tendo como base referencial os 10 indicadores da Alfabetização Científica desenvolvidos por Sasseron (2008).

\section{VERMICOMPOSTAGEM NO AMBIENTE ESCOLAR}

A vermicompostagem pode ser definida como a transformação da matéria orgânica, resultante da ação combinada das minhocas e da microflora que vive no seu trato digestivo (AQUINO; ALMEIDA; SILVA, 1992). Segundo Lourenço e Coelho (2012), o processo representa uma possibilidade de envolvimento da comunidade escolar em um processo sustentável de tratamento de resíduos orgânicos produzidos na escola, com produção de vermicomposto, um fertilizante natural de alta qualidade.

Os principais resíduos que podem ser adicionados ao sistema são gramíneas, folhas mortas, restos crus de hortaliças e cascas de frutas. Ao passar pelo trato digestório das minhocas, elas secretam enzimas capazes de degradar proteínas, gordura, celulose e carboidratos. As minhocas são, portanto, capazes de promover a transformação da matéria orgânica presente no solo, convertendo-a em vermicomposto. É importante destacar, porém, que alimentos cozidos não devem ser adicionados às composteiras, pois eles podem causar mau cheiro, que podem atrair insetos, assim como frutas críticas que acidificam o meio e afugentam as minhocas (FIORI, 2004).

No âmbito escolar, a vermicompostagem estimula a realização da coleta seletiva dos resíduos, promovendo o tratamento dos resíduos orgânicos na própria escola de uma forma sustentável e eficiente, favorecendo a Educação Ambiental junto à comunidade escolar e oportunizando o contato dos alunos com práticas agrícolas sustentáveis (LOURENÇO; COELHO, 2012).

A geração e o gerenciamento de resíduos orgânicos é um desafio na sociedade contemporânea, que atualmente transforma um ativo, que é o resíduo orgânico não cozido, em um passivo à medida que encaminha o mesmo para o Aterro Sanitário ou Lixão. $O$ cidadão brasileiro gera em média $1 \mathrm{Kg}$ de resíduos, sendo que cerca de $40 \%$ do total gerado é composto por resíduo orgânico (Brasil, 2015). Quando o tema é abordado no processo educativo, estimula a reflexão em relação às mudanças de hábitos e consumo da sociedade, conforme preconizado pelo Objetivo de Desenvolvimento Sustentável (ODS) 12 - consumo e produção responsáveis (ONU Brasil, 2015), buscando a sensibilização dos alunos acerca dos desafios atuais relacionados à problemática ambiental. As crianças e jovens podem representar um importante agente de mudança nas suas famílias e nos diferentes contextos em que vivem, sendo assim, precisam ser preparados para levar os elementos de aprendizagem, que ocorreram em sala de aula, às suas casas (REIS, 2013), replicando o aprendizado nas suas ações do cotidiano na sociedade. 


\section{ALFABETIZAÇÃO CIENTÍFICA}

A Alfabetização Científica (AC) é um processo de compreensão e aplicação de significados acerca dos assuntos científicos para melhor entender o mundo. Ela oportuniza a vivência de situações pedagógicas nas quais o educando possa adquirir habilidades e atitudes que auxiliarão no entendimento, não só do fenômeno em estudo, mas também das relações deste conhecimento com o mundo que os cerca (LORENZETTI; DELIZOICOV, 2001).

Teixeira (2013), preconiza que a AC diz respeito a tudo que envolve a leitura e escrita de um texto científico, como a construção de entendimento e análise de informações. É um processo fundamental para formar alunos críticos e construtores do conhecimento.

Com o propósito de evidenciar se o processo de Alfabetização Científica está se desenvolvendo entre os alunos, Sasseron e Carvalho (2008), destacam a importância dos indicadores de AC. Segundo as autoras, os indicadores representam competências próprias das ciências e do fazer científico, utilizados na resolução, discussão e divulgação de problemas, em que se dá a busca por relações entre o que se vê e o problema investigado e as construções mentais que levam o entendimento dele.

Sasseron e Carvalho (2008), dispõem os indicadores de AC em três grupos, sistematizados no Quadro 1:

Quadro 1 - Indicadores de Alfabetização Científica

\begin{tabular}{|c|c|}
\hline & $\begin{array}{c}\text { Indicadores } \\
\text { de Alfabetização Científica }\end{array}$ \\
\hline $\begin{array}{l}\text { GRUPO } 1 \text { - Obtenção de } \\
\text { dados. } \\
\text { Seriação, organização e } \\
\text { classificação das } \\
\text { informações. }\end{array}$ & $\begin{array}{l}\text { Grupo de indicadores relacionados ao trabalho com os } \\
\text { dados obtidos em uma investigação. A seriação pode ser } \\
\text { entendida como uma lista de dados trabalhados quando se } \\
\text { almeja o estabelecimento de bases para a ação. A } \\
\text { organização surge quando se discute o modo como o } \\
\text { trabalho foi realizado. A classificação é um momento de } \\
\text { ordenação dos elementos com os quais se está trabalhando, } \\
\text { procurando estabelecer relações entre eles. }\end{array}$ \\
\hline $\begin{array}{l}\text { GRUPO } 2 \text { - Estruturação } \\
\text { do pensamento. } \\
\text { Raciocínio lógico e } \\
\text { raciocínio proporcional }\end{array}$ & $\begin{array}{c}\text { Grupo relacionado à estruturação do pensamento que } \\
\text { molda as afirmações feitas e as falas promulgadas durante } \\
\text { as aulas de Ciências. O raciocínio lógico se relaciona à } \\
\text { maneira como as ideias são desenvolvidas e o pensamento } \\
\text { é exposto; o raciocínio proporcional refere-se à forma como } \\
\text { as variáveis se relacionam entre si. }\end{array}$ \\
\hline $\begin{array}{c}\text { GRUPO } 3 \text { - } \\
\text { Estabelecendo relações. } \\
\text { Levantamento e teste de } \\
\text { hipóteses, justificativa, } \\
\text { previsão e explicação. }\end{array}$ & $\begin{array}{l}\text { Neste grupo concentram-se indicadores relacionados à } \\
\text { procura do entendimento da situação analisada. O } \\
\text { levantamento de hipóteses procura alçar suposições acerca } \\
\text { de um tema, que serão colocadas à prova durante o teste } \\
\text { das hipóteses. A justificativa aparece quando uma } \\
\text { afirmação proferida lança mão de uma garantia, tornando- } \\
\text { se mais segura. A previsão é explicitada quando se afirma } \\
\text { uma ação e/ou fenômeno que se sucede a certos } \\
\text { acontecimentos. A explicação, por fim, surge quando se } \\
\text { busca relacionar informações e hipóteses já levantadas. }\end{array}$ \\
\hline
\end{tabular}


Sasseron e Carvalho (2008), destacam que a presença de um indicador não inviabiliza a presença de outro. Os indicadores são importantes para analisar e avaliar as argumentações que são realizadas na sala de aula, principalmente quando os alunos tentam justificar ou explicar uma ideia referente a um determinado fenômeno.

\section{SEQUÊNCIA DIDÁTICA}

Uma Sequência Didática (SD), de acordo com os princípios de Zabala (1998), representa um "conjunto de atividades ordenadas, estruturadas e articuladas para a realização de certos objetivos educacionais, que têm um princípio e um fim conhecidos, tanto pelos professores como pelos alunos". O mesmo autor declara que o objetivo de uma sequência didática deve ser "[...]introduzir nas diferentes formas de intervenção aquelas atividades que possibilitem uma melhora na nossa atuação nas aulas [...]" (ZABALA, 1998, p. 54).

Para Zabala (1998), as sequências didáticas indicam a importância das intenções educacionais. Ela deve partir de uma atividade motivadora relacionada a uma situação conflitante da realidade dos alunos, buscando a explicação de perguntas ou problemas relacionados à situação colocada.

\section{METODOLOGIA}

Esta pesquisa foi realizada a partir de uma abordagem qualitativa (GRESSLER, 2003), do tipo intervenção pedagógica (DAMIANI et al., 2013, p. 58). Associada ao trabalho prático da vermicompostagem, elaborou-se uma sequência didática (Quadro 3), tendo como referência Zabala (1998), com as atividades agrupadas de acordo com os momentos pedagógicos, propostos por Delizoicov, Angotti e Pernambuco (2009). A pesquisa foi aprovada pelo Comitê de Ética de Pesquisa CAAE:79367417.5.0000.5547 da UTFPR com o parecer no 2.533.744.

A verificação das produções escritas - os diários de bordo - foi baseada no método de análise de conteúdo de Bardin (2016). Foram utilizadas como categoria de análise os Indicadores de Alfabetização Científica propostas por Sasseron (2008). Foram analisados 56 diários, organizados em 11 trios e 1 dupla. A organização das subcategorias para agrupar os indicadores de AC foram definidos pelas autoras do artigo, com o objetivo de facilitar a sistematização dos resultados. No Quadro 2 estão demonstrados a organização das subcategorias da AC e seus respectivos indicadores. 
Quadro 2 - Organização da categoria de análise Indicadores de Alfabetização Científica em subcategorias

\section{Indicadores de Alfabetização Científica}
GRUPO 1 - Obtenção de dados. Seriação, organização e classificação das informações.

GRUPO 2 - Estruturação do pensamento. Raciocínio lógico e raciocínio proporcional.

GRUPO 3 -

Estabelecendo relações. Levantamento e teste de hipóteses, justificativa, previsão e explicação.
Grupo de indicadores relacionados ao trabalho com os dados obtidos em uma investigação. A seriação pode ser entendida como uma lista de dados trabalhados quando se almeja o estabelecimento de bases para a ação. A organização surge quando se discute o modo como o trabalho foi realizado. A classificação é um momento de ordenação dos elementos com os quais se está trabalhando, procurando estabelecer relações entre eles.

Grupo relacionado à estruturação do pensamento que molda as afirmações feitas e as falas promulgadas durante as aulas de Ciências. $O$ raciocínio lógico se relaciona à maneira como às ideias são desenvolvidas e o pensamento é exposto; o raciocínio proporcional refere-se à forma como as variáveis se relacionam entre si.

Neste grupo concentram-se indicadores relacionados à procura do entendimento da situação analisada. 0 levantamento de hipóteses procura alçar suposições acerca de um tema, que serão colocadas à prova durante o teste das hipóteses. A justificativa aparece quando uma afirmação proferida lança mão de uma garantia, tornandose mais segura. A previsão é explicitada quando se afirma uma ação e/ou fenômeno que se sucede a certos acontecimentos. A explicação, por fim, surge quando se busca relacionar informações e hipóteses já levantadas.

Fonte: Autores (2019).

A Sequência Didática para o tema vermicompostagem, baseada nos 3 momentos pedagógicos propostos por Delizoicov, Angotti e Pernambuco (2009). A problematização inicial acerca da geração e gerenciamento de resíduos justificou a importância da vermicompostagem como alternativa para a redução do volume de resíduos produzidos diariamente no ambiente escolar. A organização do conhecimento possibilitou aos estudantes a aquisição de conhecimentos relacionados as características das minhocas e os cuidados que devem ser adotados durante a montagem e manutenção dos vermicompostores. A aplicação do conhecimento ocorreu, sobretudo, durante o desenvolvimento do trabalho prático com os sistemas de vermicompostagem. As atividades desenvolvidas estão sistematizadas no Quadro 3. 


\begin{tabular}{|c|c|c|c|}
\hline & Tempo/Conteúdo & Recursos & Metodologia \\
\hline 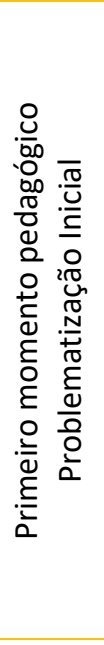 & $\begin{array}{l}\text { Tempo estimado: } \\
\text { 4h/aulas de } 50 \\
\text { minutos. } \\
\text { Conteúdos: } \\
\text { Geração e } \\
\text { gerenciamento de } \\
\text { resíduos sólidos no } \\
\text { país. }\end{array}$ & $\begin{array}{l}\text { Papel sulfite, lápis } \\
\text { grafite, lápis de cor. } \\
\text { Laboratório de } \\
\text { Informática, voucher } \\
\text { de acesso à Internet, } \\
\text { smartphones e } \\
\text { cartilha sobre } \\
\text { vermicompostagem. }\end{array}$ & $\begin{array}{l}\text { - Roda de conversa acerca dos } \\
\text { conhecimentos prévios dos } \\
\text { alunos sobre a geração e o } \\
\text { gerenciamento de resíduos no } \\
\text { Brasil, com representação } \\
\text { através de desenho. } \\
\text { - Pesquisa bibliográfica sobre } \\
\text { geração e gerenciamento de } \\
\text { resíduos sólidos no Brasil. } \\
\text { - Trechos do filme “Lixo } \\
\text { Extraordinário", para discutir os } \\
\text { aspectos socioambientais dos } \\
\text { resíduos. } \\
\text { - Sistematização das discussões } \\
\text { em diários de bordos. }\end{array}$ \\
\hline 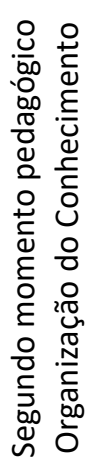 & $\begin{array}{l}\text { Tempo estimado: } \\
\text { 3h/aulas de } 50 \\
\text { minutos. } \\
\text { Conteúdos: } \\
\text { Aspectos } \\
\text { anatômicos, } \\
\text { fisiológicos das } \\
\text { minhocas. }\end{array}$ & $\begin{array}{l}\text { Laboratório de } \\
\text { Informática, } \\
\text { smartphones, } \\
\text { cartilha sobre } \\
\text { vermicompostagem. } \\
\text { Amostras de } \\
\text { minhocas em húmus, } \\
\text { papel absorvente, } \\
\text { lupa, borrifador de } \\
\text { água e roteiro de } \\
\text { aula prática. }\end{array}$ & $\begin{array}{c}\text { - Pesquisa bibliográfica sobre as } \\
\text { principais características } \\
\text { anatômicas e fisiológicas das } \\
\text { minhocas. } \\
\text { - Aula prática para a observação } \\
\text { da morfologia externa e } \\
\text { comportamento das minhocas. } \\
\text { - Sistematização das discussões } \\
\text { em diários de bordos. }\end{array}$ \\
\hline 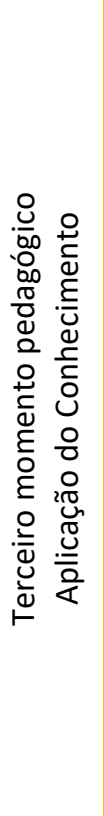 & $\begin{array}{l}\text { Tempo estimado: } \\
\text { 5h/aulas de } 50 \\
\text { minutos. } \\
\text { Conteúdos: } \\
\text { Montagem e } \\
\text { manutenção dos } \\
\text { vermicompostores. }\end{array}$ & $\begin{array}{c}\text { Laboratório de } \\
\text { Informática, } \\
\text { vouchers de acesso à } \\
\text { Internet, } \\
\text { smartphones, } \\
\text { cartilha sobre } \\
\text { vermicompostagem. } \\
\text { Vermicompostores, } \\
\text { minhocas e } \\
\text { vermicomposto, pá, } \\
\text { ancinho, faca, luvas, } \\
\text { resíduos sólidos } \\
\text { orgânicos. }\end{array}$ & $\begin{array}{l}\text { - Pesquisa bibliográfica sobre } \\
\text { aspectos históricos da } \\
\text { vermicompostagem. } \\
\text { - Pesquisa bibliográfica acerca } \\
\text { das principais características dos } \\
\text { vermicompostores, os resíduos } \\
\text { que podem ser adicionados e a } \\
\text { solução para eventuais } \\
\text { problemas que possam ocorrer } \\
\text { no decorrer do processo. } \\
\text { - Aula prática para a montagem } \\
\text { dos vermicompostores. } \\
\text { - Aula prática para a } \\
\text { manutenção dos } \\
\text { vermicompostores e } \\
\text { preenchimento das fichas de } \\
\text { controle. } \\
\text { - Sistematização das discussões } \\
\text { em diários de bordo. }\end{array}$ \\
\hline
\end{tabular}




\section{RESULTADOS E DISCUSSÕES}

As produções escritas realizadas, por meio das sistematizações em diários de bordo, forma analisadas pelas autoras, tendo como base a descrição de cada um dos indicadores. O objetivo foi verificar quais dos indicadores de Alfabetização Científica (AC) foram assimilados durante o desenvolvimento da Sequência Didática. Segundo Sasseron e Carvalho (2008), os indicadores têm como função evidenciar algumas destrezas que devem ser trabalhadas quando se deseja colocar a AC em construção com os alunos, ou seja, eles representam uma forma de avaliar se os alunos conseguiram se apropriar do conhecimento científico.

$\mathrm{Na}$ Tabela 1 estão demonstradas a relação entre os indicadores dos 12 diários $(n=12)$ analisados. Em cada diário foi possível constatar a frequência de ocorrência dos indicadores que foram identificados. Ao final da tabela é possível verificar o total da frequência de ocorrências dos indicadores de todos os diários organizados.

Tabela 1 - Unidades de análise referentes aos indicadores de Alfabetização Científica

Indicadores de Alfabetização Científica (AC)

\begin{tabular}{|c|c|c|c|c|c|c|c|c|c|c|c|}
\hline 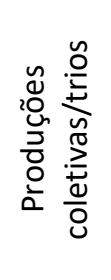 & 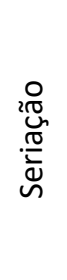 & 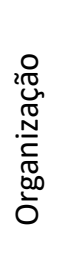 & 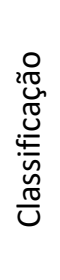 & 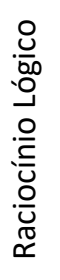 & 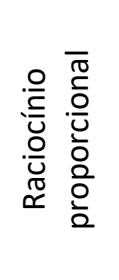 & 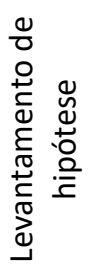 & 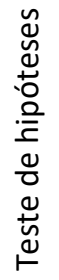 & 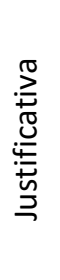 & 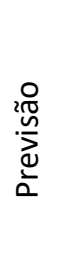 & 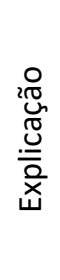 & 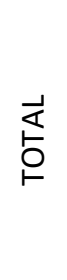 \\
\hline G01 & 0 & 2 & 2 & 2 & 2 & 0 & 0 & 1 & 1 & 2 & 12 \\
\hline G02 & 0 & 3 & 2 & 2 & 2 & 0 & 0 & 1 & 1 & 1 & 12 \\
\hline G03 & 2 & 2 & 2 & 3 & 0 & 0 & 0 & 0 & 0 & 1 & 10 \\
\hline G04 & 2 & 2 & 3 & 1 & 0 & 0 & 0 & 1 & 0 & 0 & 9 \\
\hline G05 & 2 & 2 & 2 & 1 & 1 & 0 & 0 & 1 & 1 & 0 & 12 \\
\hline G06 & 1 & 1 & 3 & 1 & 1 & 0 & 0 & 1 & 0 & 1 & 9 \\
\hline G07 & 3 & 1 & 2 & 0 & 0 & 0 & 0 & 1 & 0 & 1 & 8 \\
\hline G08 & 2 & 2 & 2 & 1 & 2 & 0 & 0 & 0 & 1 & 1 & 13 \\
\hline G09 & 1 & 0 & 2 & 0 & 1 & 0 & 0 & 0 & 0 & 2 & 8 \\
\hline G10 & 2 & 3 & 2 & 1 & 1 & 0 & 0 & 0 & 1 & 1 & 11 \\
\hline G11 & 2 & 1 & 1 & 0 & 2 & 0 & 0 & 0 & 1 & 0 & 9 \\
\hline $\mathrm{G} 12$ & 2 & 1 & 2 & 0 & 1 & 0 & 0 & 1 & 0 & 1 & 8 \\
\hline TOTAL & 19 & 20 & 25 & 12 & 13 & 0 & 0 & 7 & 6 & 11 & 121 \\
\hline
\end{tabular}

Legenda: G 01- G12 = diários das produções coletivas do grupo $01-$ grupo 12 . N=12

Fonte: Autores (2019).

Os resultados demonstrados na Tabela 1 indicam o predomínio no número de frequência de ocorrência para a subcategoria obtenção de dados. $O$ indicador 
classificação da informação, apresentou 25 ocorrências, seguido dos indicadores organização e seriação, com 20 e 19 ocorrências respectivamente. Portanto, na subcategoria obtenção de dados foi onde se verificou a maior frequência de ocorrências em relação aos demais indicadores. Os indicadores de AC para a subcategoria estruturação do pensamento, que inserem o raciocínio proporcional, no qual se verificou cerca de 13 ocorrências e o raciocínio lógico, com 12 ocorrências, se mostraram como sendo a subcategoria que apresentou a frequência intermediária de ocorrências, quando comparadas entre as 3 subcategorias. Da subcategoria estabelecendo relações, o indicador explicação, apresentou o maior número na frequência de ocorrências, na qual foram contabilizadas 11 . As menores frequências de ocorrências foram com o indicador justificativa, com 7 ocorrências, e previsão, com 6 ocorrências. Os indicadores levantamento e teste de hipóteses não apresentaram ocorrências nas produções analisadas. Neste caso, a subcategoria estabelecendo relações foi a que apresentou os indicadores com o menor número de frequência de ocorrências.

Os indicadores que mais se destacaram em frequência foram: seriação, organização e classificação das informações. Estes três indicadores são os que estão relacionados à obtenção de dados, etapa em que os alunos reconhecem as principais variáveis envolvidas nos fenômenos investigados. Estes indicadores apareceram nos relatos referentes ao processo de vermicompostagem. O indicador seriação, que estabelece as bases para a ação investigativa, fica evidente nos relatos que indicam as principais características das minhocas (19 ocorrências em $\mathrm{n}=12$ ). Os alunos foram capazes de indicar essas informações de forma satisfatória, demonstrando ter assimilado os conceitos importantes relacionados à sobrevivência das minhocas nos sistemas de vermicompostagem. Isso fica evidente durante a análise dos diários, que foram organizados em duplas. Esses diários foram organizados durante as aulas e identificados por grupo e número do diário (G01D01, por exemplo). Durante as transcrições dos textos, foram realizadas correções de linguagem pelas autoras, para este artigo, com o objetivo de facilitar a leitura.

Fizemos aula prática da minhoca e aprendemos que o corpo da minhoca é divido em anéis, possuem cerdas que ajudam elas a se movimentar. A minhoca tem boca e ânus, o clitelo fica mais perto da boca. Ele serve para formar o casulo onde ficarão os óvulos e espermatozoides (G01D02).

Nesse excerto foi possível perceber que, após a pesquisa bibliográfica e a aula prática, as equipes conseguiram elencar informações relevantes sobre as principais características morfofisiológicas das minhocas. Segundo Silva (2018), o indicador seriação tem como objetivo agrupar dados já trabalhados e/ou experiências prévias dos alunos, estabelecendo base para o problema trabalhado.

O indicador organização aparece sobretudo nos relatos referentes à montagem e manutenção dos sistemas da vermicompostagem, quando os alunos descrevem de que forma o trabalho foi realizado. Este indicador pode ser encontrado durante $o$ arranjo de informações novas ou já elencadas anteriormente e ocorre tanto no início da proposição de um tema quanto na retomada de uma questão, quando ideias são relembradas (SASSERON, 2008). Isso pode ser evidenciado no seguinte relato: 
minhocas vão ficar. Dividimos 218 minhocas em dois potes com 109 minhocas em cada, no vermidigestor com canos colocamos papel para as minhocas não caírem para baixo (G05D03).

A organização das informações aparece neste fragmento quando os alunos indicam os cuidados que devem ser adotados durante a aula e descrevem a forma como o experimento foi realizado. Para Silva (2018), este indicador possibilita a estruturação de ideias e a tomada de consciência das ações e reações ligadas à situação trabalhada.

O indicador classificação aparece quando os alunos organizam e ordenam os elementos, estabelecendo relações entre eles. Este indicador aparece nos relatos referentes a montagem e manutenção dos vermidigestores, como é possível observar no seguinte excerto:

[...] montamos os sistemas em caixas pretas porque elas não gostam de luz, adicionamos substrato e fizemos observações diariamente nos dois sistemas porque se colocar muita comida, elas vão ter dificuldade de digerir e vai acumular moscas. Também colocamos folhas secas para reduzir a umidade e equilibrar o nitrogênio, que vira amônia (G08D05).

Neste fragmento ficou evidente que os alunos, ao indicaram a importância de montar os vermidigestores com as caixas pretas, compreenderam que este material propicia um ambiente mais adequado, porque as minhocas são sensíveis à luz e podem desidratar. Assim, é perceptível que eles conseguiram estabelecer as relações entre as características das minhocas, previamente estudadas com os cuidados e o tipo de ambientação que devem ser adotados durante a montagem e manutenção dos vermidigestores.

A alta ocorrência dos indicadores seriação, classificação e organização da informação demonstra que os alunos buscaram alternativas que culminaram na resolução de problemas observados durante o processo de investigação, estabelecendo relações entre os conceitos teóricos e os problemas práticos observados. As autoras Sasseron e Carvalho (2008), afirmam que estes três indicadores são relevantes porque permitem reconhecer as variáveis envolvidas no fenômeno investigado, mesmo que a investigação ainda não esteja pronta em estabelecer relações entre as variáveis ou indicar a explicação do fenômeno.

Os indicadores raciocínio lógico e raciocínio proporcional aparecem com uma frequência intermediária. O indicador raciocínio lógico, caracterizado como a maneira que o pensamento é exposto de acordo com a forma como as ideias se desenvolvem, apareceu com 12 ocorrências nas produções $(n=12)$, o que demonstra a provável dificuldade dos alunos em articular determinadas ideias. Estes resultados podem estar demonstrando que, na maior parte do processo ensino-aprendizagem, os alunos conseguem reproduzir conceitos trabalhados em sala de aula, mas não conseguem extrapolar estes saberes para situações diárias por eles vivenciadas, assim como possuem dificuldade em estabelecer uma sequência lógica para projetos, porque estes não são praticados no cotidiano escolar. A presença desse indicador foi observada no seguinte relato: estão longe (G01D01). 
Nesse excerto é possível perceber a compreensão em relação ao problema exposto, e a tomada de consciência de que o descarte incorreto dos resíduos pode acarretar danos em locais muito distantes do local de sua geração. Lorenzetti e Delizoicov (2001), enfatizam a necessidade de serem trabalhadas habilidades entre os alunos referentes ao processo de construção do conhecimento científico, além de destacarem a importância de fazer com que os alunos enxerguem as relações existentes entre os conhecimentos sistematizados em sala de aula e os assuntos que fazem parte de seu cotidiano.

O indicador raciocínio proporcional, apareceu com 13 ocorrências nas produções $(n=12)$, sobretudo naquelas relacionadas à montagem e manutenção dos vermidigestores. Isso pode ser evidenciado nos seguintes excertos:

Não colocamos frutas como a laranja porque são ácidas e as minhocas poderiam fugir (G09D04).

Em 24/09/2018, observamos grande quantidade de moscas nos dois sistemas porque está muito úmido. Retirar o chorume e adicionar folhas secas ajudará a reduzir a umidade (G01D02).

É possível perceber, nos fragmentos acima, que as equipes foram capazes de estabelecer relações entre as características dos animais e o dos vermidigestores construídos para a vermicompostagem. O indicador raciocínio proporcional foi observado quando os alunos descreveram que frutas cítricas não poderiam ser adicionadas porque tornariam o meio ácido e isso causaria a fuga das minhocas. No trecho que indica a importância da adição de folhas secas para reduzir a umidade e evitar a presença de Drosophilas (mosquinhas da fruta) nos vermidigestores durante a vermicompostagem, este indicador também foi evidenciado. Lorenzetti (2000), afirma que uma pessoa alfabetizada cientificamente possui entendimento geral dos fenômenos básicos, é capaz de interpretar informações referentes à ciência e à tecnologia e possui capacidade de compreender, discutir e assumir uma posição frente a esses assuntos.

A baixa frequência de ocorrências dos indicadores - raciocínio lógico e raciocínio proporcional - pode estar demonstrando a dificuldade que os alunos possuem em intercalar as diferentes variáveis para o tema resíduos sólidos, estabelecendo relações entre elas. Esses indicadores estão relacionados à estruturação do pensamento, que molda as considerações feitas e proclamadas durante as aulas de Ciências (SASSERON; CARVALHO, 2008).

Os indicadores levantamento e teste de hipóteses, justificativa, previsão e explicação compõem um grupo associado ao estabelecimento de relações entre as variáveis envolvidas com o fenômeno estudado. O levantamento e teste de hipóteses não foi evidenciado nas produções analisadas. A não ocorrência desses indicadores provavelmente se deve pelo fato de os relatos/diários descreverem as atividades já desenvolvidas, e que os alunos não estão acostumados a descrever questionamentos. Isto demonstra, de certa forma, que existe no âmbito escolar a falta de cultura de registrar questionamentos/levantamento, hipóteses/teste de hipóteses, que de certa forma são essenciais para despertar e desafiar o processo lógico do pensamento, ou seja, que são a base para a alfabetização científica.

O indicador previsão, observado quando uma ação/fenômeno sucede certos acontecimentos, foi observado nos relatos relacionados aos cuidados que devem ser adotados durante a montagem e manutenção dos vermidigestores. A ocorrência do indicador previsão foi observada em 6 relatos $(n=12)$, onde os alunos 
relacionam as características das minhocas aos cuidados que devem ser adotados durante a montagem dos vermidigestores, como pode ser observado nos relatos abaixo transcritos:

No dia 16/08, o cheiro estava muito forte no vermidigestor com furos e houve uma redução no número de minhocas. Isso ocorreu porque os furos ficaram entupidos, faltou oxigênio e o meio ficou tóxico (G02D04).

O indicador explicação, que apareceu com uma frequência intermediária nos relatos (11 ocorrências para $n=12$ ), procura relacionar informações e hipóteses levantadas. Este indicador ficou evidente quando os alunos utilizam informações previamente estudadas, buscando soluções para os problemas observados durante a manutenção dos vermidigestores, o que pode ser evidenciado no seguinte excerto:

Durante o projeto os vermidigestores ficaram no laboratório; isso é importante por causa dos bichos que poderiam comer as minhocas. Além disso, se as caixas ficassem no sol iria esquentar e as minhocas morreriam desidratadas (G03D04).

O indicador justificativa foi observado com ocorrências em 7 produções. Este indicador manifesta-se quando uma afirmação lança mão de uma garantia, fazendo com que a afirmação se torne mais segura. Este indicador ficou evidente nos diários que destacam a importância da vermicompostagem como ferramenta de sensibilização da importância da separação correta dos resíduos, além da reutilização e reciclagem dos resíduos produzidos no ambiente escolar. Isso pode ser observado no seguinte relato:

\footnotetext{
A vermicompostagem é um tipo de compostagem que usa as minhocas. É interessante porque dá para reduzir um pouco dos resíduos e colocar no vermidigestores; depois que as minhocas as comiam e transformavam resíduos em húmus e chorume, que pode ser colocado como adubo para a planta (G02D04).
}

Este último indicador aparece quando a equipe argumenta sobre a importância da vermicompostagem, ao afirmar que a prática contribui para a redução da quantidade de resíduos gerados no ambiente escolar.

A partir da análise da Tabela 1 foi possível observar a ocorrência de 8 indicadores de AC: seriação, organização, classificação, raciocínio lógico, raciocínio proporcional, justificativa, previsão e explicação. Os indicadores levantamento e teste de hipóteses não aparecem nos diários analisados. $O$ indicador levantamento de hipóteses possui um caráter pedagógico importante no processo de construção do conhecimento científico, pois é por meio dele que os alunos expõem seus conhecimentos prévios, utilizados na tomada de decisão e que possibilitam testar e traçar uma explicação para um determinado fenômeno (SILVA, 2018). O teste de hipóteses é observado quando os alunos aplicam seus conhecimentos prévios e observam os resultando, verificando se as soluções por eles apontadas foram ou não confirmadas, sendo que este processo é o elemento facilitador para a estruturação de ideias e a organização do conhecimento. A falta ou baixa frequência de ocorrências destes indicadores podem estar demonstrando que os processos de investigação e problematização dos conteúdos estão deficientes nas aulas de ciências, e, portanto, não estão fazendo parte do processo ensinoaprendizagem. Isso talvez seja fruto da maneira como os conteúdos são 
trabalhados no contexto tradicional do processo ensino-aprendizagem, ou seja, de forma linear e a-histórica, considerando sobretudo os produtos da Ciência, e o repasse de conteúdo curricular sem contextualização.

A ocorrência dos indicadores classificação, seriação e organização das informações que apareceram com maior frequência de ocorrências nas análises, poderia ser explicado devido a capacidade dos alunos em memorizar, reproduzir e categorizar as informações. Nem sempre, porém, os alunos conseguem estabelecer relações entre as informações (raciocínio lógico e proporcional), e/ou utilizá-las para prever, explicar ou justificar um fenômeno ou uma ação. Neste sentido, a autora Sasseron (2015) preconiza que o processo de AC deve ser encarado como meta no ensino de ciências, objetivando a construção de conhecimentos onde os alunos superem a memorização, num processo que leve o aluno a "fazer ciência", por meio de um trabalho de investigação que almeje a resolução de problemas e a utilização dos conceitos científicos no cotidiano dos alunos.

Os três últimos indicadores - justificativa, explicação e previsão - aparecem com uma baixa frequência nos relatos analisados. Eles estão estreitamente relacionados e demonstram as particularidades do fenômeno observado. A baixa ocorrência destes indicadores nos relatos observados demonstra a fragilidade na construção de relações e a falta do estabelecimento de relações entre as variáveis envolvidas no fenômeno estudado, a vermicompostagem. Além disso, estes indicadores deveriam evidenciar a capacidade dos alunos de explicitar um padrão de comportamento que pode ser estendido a outras situações (SASSERON, 2008). $\mathrm{O}$ resultado demonstra a fragilidade do processo ensino-aprendizagem para o estabelecimento de relações para a explicação de fenômenos.

\section{CONSIDERAÇÕES FINAIS}

A aplicação da sequência didática sobre vermicompostagem, embora baseada nos três momentos pedagógicos, manteve a perspectiva de um ensino investigativo conforme proposto por Sasseron (2008), uma vez que o objetivo estava em analisar a presença dos indicadores propostos por esta autora e que estão associados a uma abordagem didática dessa natureza. Assim, a SD possibilitou o envolvimento dos alunos em um trabalho de investigação, no qual os conceitos foram construídos de forma coletiva, superando a mera transmissão e memorização dos conteúdos. Desta forma foi possível verificar como o desenvolvimento da vermicompostagem, como estratégia pedagógica para o desenvolvimento da AC na escola, permitiu abordar os conteúdos de Ciências de forma instigante, estimulando os alunos a se tornarem protagonistas no processo de construção do conhecimento.

A aplicação da sequência didática sobre a vermicompostagem, associada ao desenvolvimento do trabalho prático, favoreceu as discussões acerca da problemática ambiental relacionada aos resíduos sólidos produzidos pela comunidade na escola e/ou em seus lares. Possibilitou, ainda, a análise desta problemática almejando extrapolar os conceitos discutidos e sistematizados durante as aulas, buscando promover a sensibilização dos alunos necessária para a mudança de hábitos que visam a transformação social baseada na sustentabilidade socioambiental. 
A análise dos 12 relatos produzidos pelos alunos permitiu identificar que os indicadores seriar, classificar e organizar as informações são alcançados de forma satisfatória, demonstrando que este pode ser considerado um ponto forte no ensino de Ciência. Porém ficou evidente que existem falhas na forma de desenvolver questionamentos durante as aulas de Ciências, o que pode ser observado devido à baixa ocorrência dos indicadores: levantamento e teste de hipóteses. Além disso, a pequena ocorrência dos indicadores justificativa, previsão, explicação, raciocínio lógico e raciocínio proporcional, demonstram que há dificuldade em extrapolar conceitos apreendidos em sala de aula para explicar determinados fenômenos, provavelmente porque não são situações desenvolvidas e exercitadas ao longo do processo de ensino e aprendizagem aplicados na forma clássica. Neste contexto, estimular atividades práticas pode ser uma estratégia pedagógica importante para ser desenvolvida em aulas de Ciências, visando não limitar a reprodução de experimentos alienada de uma análise crítica dos conteúdos. É fundamental que os alunos possam estabelecer relações entre os conceitos adquiridos durante as aulas de Ciências, para resolver problemas práticos do seu cotidiano. 


\title{
THE VERMICOMPOST AS THEME FOR THE PROMOTION OF SCIENTIFIC LITERACY
}

\begin{abstract}
This article makes a qualitative analysis of a Didactic Sequence (DS) for Elementary School, elaborated with the vermicomposting theme to promote Scientific Literacy (SL). SD is an organized and applied teaching methodology to facilitate learning. SL is a continuous process of understanding and applying scientific meanings and concepts. The vermicomposting is the recycling of organic matter resulting from the action of earthworms and microorganisms, which was applied in the DS to promote the research process and SL. The students recorded the contents assimilated during DS in logbooks, which were analyzed in light of the 10 indicators of SL proposed by Sasseron (2008). The results of the indicators were: high - for data collection; mean - for structuring thought; low - to establish relationships, the latter being the element that should be better worked through teaching.
\end{abstract}

KEYWORDS: Didactic Sequence. Indicators. Pedagogical Strategy. 


\section{REFERÊNCIAS}

AQUINO, A. M.; ALMEIDA, D. L.; SILVA, V. F. Utilização de minhocas na estabilização de resíduos orgânicos: vermicompostagem. Embrapa AgrobiologiaComunicado Técnico (INFOTECA-E), 1992.

BARDIN, L. Análise de conteúdo. Lisboa: Edições 70, 2016.

BRASIL. Levantamento MMA 2015. <http://www.mma.gov.br/mma-emnumeros/residuos-solidos>. Acesso em: 02 jun. 2015.

DAMIANI, M. F. et al. Discutindo pesquisas do tipo intervenção pedagógica. Cadernos de Educação, n. 45, p. 57 - 67, jul./ago. 2013.

DELIZOICOV, D.; ANGOTTI, J. P.; PERNAMBUCO, M. M. Ensino de ciências: fundamentos e métodos. 3. ed. São Paulo. Cortez, 2009. (Docência em formação Ensino fundamental).

FIORI, A. A. Minhocultura. Boletim Técnico - CECOR - SAA/CATI, n. 242, 2004.

GRESSLER, L. A. Introdução à pesquisa. São Paulo: Loyola, 2003.

JACOBI, P R. Educação ambiental: o desafio da construção de um pensamento crítico, complexo e reflexivo. Educação e Pesquisa, v. 31, n. 2, p. 233-250, maio/jun. 2005.

LORENZETTI, L. Alfabetização científica no contexto das séries iniciais. Dissertação (Mestrado em Educação) - Universidade Federal de Santa Catarina, Florianópolis, 2000.

LORENZETTI, L.; DELIZOICOV, D. Alfabetização científica no contexto das séries inicias. Ensaio - Pesquisa em Educação em Ciências, v. 3, n. 1, jun. 2001.

LOURENÇO, N.; COELHO, I. Vermicompostagem nas escolas: manual prático do professor. 1. ed. Lisboa (POR): Sítio do Livro, 2012.

MORAES, M. C. O paradigma educacional emergente. São Paulo: Papirus, 2002.

ONU Brasil. Agenda 2030. <https://nacoesunidas.org/pos2015/agenda2030/>. 
REIS, P. Da discussão à ação sócio-política sobre controvérsias sócio científicas: uma questão de cidadania. Ensino de Ciências e Tecnologia em Revista. v. 3, n. 1, 2013.

SASSERON, L. H. Alfabetização científica no ensino fundamental: estrutura e indicadores deste processo em sala de aula. Tese (Doutorado em Educação) Universidade de São Paulo, São Paulo, 2008.

SASSERON, L. H. Alfabetização científica, ensino por investigação e argumentação: relações entre ciências da natureza e escola. Ensaio Pesquisa em Educação em Ciências, v. 17, n. esp., p. 49-67, nov. 2015.

SASSERON, L. H.; CARVALHO, A. M. P. Almejando a alfabetização científica no ensino fundamental: a proposição e a procura de indicadores do processo. Investigações em Ensino de Ciências, v. 13, n. 3, p. 333-352, 2008.

SILVA, V. R. Contribuições de uma sequência didática para a promoção da alfabetização científica nos anos iniciais. 2018. 288 f. Dissertação (Mestrado em Educação em Ciências e em Matemática) - Universidade Federal do Paraná, Curitiba, 2018.

TEIXEIRA, F. M. Alfabetização científica: questões para reflexão. Ciência Educação, v. 19, n. 4, p. 795-809, 2013.

THIESEN, J. S. A interdisciplinaridade como um movimento articulador no processo ensino-aprendizagem. Revista Brasileira de Educação, v. 13, n. 39, 2008.

ZABALA, A. A prática educativa: como ensinar. Porto Alegre: Artmed, 1998. 
Recebido: 06 jun. 2019.

Aprovado: 05 nov. 2019

DOI: $10.3895 /$ rbect.v13n3.10199

Como citar: TOREZIN, A. F.; KAICK, T. S. A vermicompostagem como temática para a promoção da

alfabetização científica. Revista Brasileira de Ensino de Ciência e Tecnologia, Ponta Grossa, v.13, n. 3,

p. 168-185, set./dez. 2020. Disponível em: <https://periodicos.utfpr.edu.br/rbect/article/view/10199>. Acesso em: $X X X$.

Correspondência: Aline Ferreira Torezin - alinetorezin@gmail.com

Direito autoral: Este artigo está licenciado sob os termos da Licença Creative Commons-Atribuição 4.0

Internacional.

(c) (i) 